\title{
Influence of Pulsed Fiber Laser Radiation on Surface Morphology and Electrical Properties of $\mathrm{Si} / \mathrm{SiO}_{2}$ Structure
}

\author{
Dmitry Polyakov, Albert Skvortsov, Vadim Veiko \\ ITMO University, St.-Petersburg, Kronverkskiy pr. 49, Russia \\ E-mail: polyakovdmitry1988@gmail.com
}

\begin{abstract}
The regularities of microrelief formation on the surface of $\mathrm{Si} / \mathrm{SiO}_{2}$ structure under the action of pulsed fiber laser radiation with intensity lower than $\mathrm{SiO}_{2}$ damage threshold are studied. Obtained surface morphology modification accompanied with changes in capacitance-voltage characteristics of modified area.
\end{abstract}

DOI: $10.2961 / \mathrm{jlmn} .2015 .03 .0006$

Keywords: wave-like microstructures, $\mathrm{Si} / \mathrm{SiO}_{2}$ structure, ytterbium fiber laser

\section{Introduction}

Laser microfabrication of $\mathrm{Si}$ and Si-based materials is a promising direction in the field of laser processing of electrotechnical materials. This trend is actual due to a potential of micro- and nano-structures development which specific properties can open perspectives for creation of new types of electronic devices. At present time there are a lot of works [1-3] devoted to laser microfabrication of silicon surface, much less attention is given to silicon silicon dioxide structure (for example, one can see $[4,5]$ ), but it is the base for most modern microelectronic MOS devices. Since there is a big practical interest to $\mathrm{Si} / \mathrm{SiO}_{2}$ structure it is appropriate to use lasers which work well from the perspective of their possible use in industry. Ytterbium fiber laser is one of them. Such advantages of this laser as high efficiency, long service life, high beam quality, etc are well known. It is also possible to irradiate sample with high power nanosecond pulses (pulse energy is about $1 \mathrm{~mJ}$ ) at high repetition rate (up to $100 \mathrm{kHz}$ ). This mode attracts an attention of researchers due to possible thermomechanical laser action. In particular authors have already made experiments on exposure of $\mathrm{Si} / \mathrm{SiO}_{2}$ structure with series of $\mathrm{Nd}$ :YAG-laser pulses at kilohertz repetition rate. As a result significant increase of a resistance of the $\mathrm{SiO}_{2}$ to chemical etching was observed. However, these studies were not completed.

Let's also mention the paper [6] where specified prerequisites of possibility of obtaining nanocomposite materials ( $\mathrm{Si}$ nanoclusters in $\mathrm{SiO}_{2}$ layer) through direct laser irradiation of $\mathrm{Si} / \mathrm{SiO}_{2}$ structure were discussed. It is known that such nanostructures are promising for development of silicon-based photonic devices [7], and non-volatile memory devices [8].

For the foregoing reasons a comprehensive investigation of interaction of ytterbium fiber laser pulsed radiation with $\mathrm{Si} / \mathrm{SiO} 2$ structure is an actual scientific problem. The aim of the current work is to contribute to the solution of this problem.

In this work we studied regularities of microrelief formation on the surface of Si covered by its thermal oxide $\left(\mathrm{Si} / \mathrm{SiO}_{2}\right.$ structure) under the action of pulsed fiber laser radiation with intensity lower than $\mathrm{SiO}_{2}$ damage threshold. Surface morphology of obtained microstructures was studied by methods of optical and scanning probe (AFM) microscopy. In the study of electrical properties of modified area the measuring methods of high frequency capacitance-voltage $(\mathrm{C}-\mathrm{V})$ characteristics and currentvoltage $(\mathrm{V}-\mathrm{A})$ characteristics were used.

\section{Experimental details}

In our experiments we used monocristalline silicon plates with crystallographic surface orientation (100) covered by thermally grown dioxide with different thicknesses $(35,150$ and $500 \mathrm{~nm})$ as samples. Total plate thickness was about $380 \mu \mathrm{m}$. Irradiation of the samples was carried out by scanning ytterbium pulsed laser beam at wavelength $1.07 \mu \mathrm{m}$ from the oxide surface. Beam scanning was realized on the base of a biaxial galvanometer scanner - the trajectories are shown at fig. 1. Total size of irradiated area was $2 \times 2 \mathrm{~mm}$. Action of laser radiation on $\mathrm{Si} / \mathrm{SiO}_{2}$ structure is completely defined by following parameters: average power $\mathrm{P}$, scanning speed $\mathrm{v}$, pulse repetition rate $f$, distance between scanning lines $L_{y}$, beam diameter $d$ and pulse duration $t_{p}$. During the exposure the beam diameter $\mathrm{d}=120 \mu \mathrm{m}$ and pulse duration $\mathrm{tp}=100 \mathrm{~ns}$ remained constant. Laser beam had a Gaussian profile, mentioned value of a beam diameter corresponds to $\mathrm{e}^{-2}$ level. Parameters $\mathrm{P}, \mathrm{v}, \mathrm{f}, \mathrm{L}_{\mathrm{y}}$ were variable. We used following irradiation schemes: single pulses $\left(v>d f, L_{y}>d\right)$, $\mathrm{x}$-axis overlapping $\left(\mathrm{v}<<\mathrm{df}, \mathrm{L}_{\mathrm{y}}>\mathrm{d}\right)$, both axis overlapping $(\mathrm{v}<<\mathrm{df}, \mathrm{Ly}<<\mathrm{d})$ with one scan direction (see fig. 1a), both

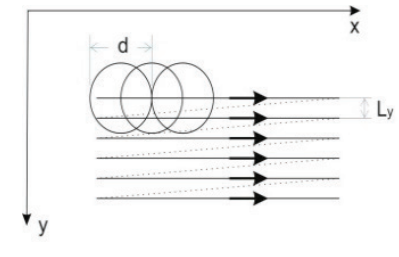

a

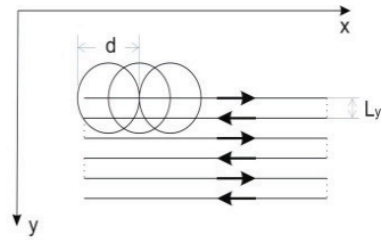

b
Fig.1 The beam motion pattern: $a$ - one directional scan, $b$ - two directional scan (scan direction shown by black arrow) 
axis overlapping with changing scan direction to opposite when the beam feeds a line (see fig. 1b).

In all experiments treatment was made with intensity, which was below $\mathrm{SiO}_{2}$ damage threshold.

\section{Results}

As a result of irradiation by single pulses with energy $0.17 \mathrm{~mJ}$ (corresponding power density $\mathrm{q}=1.5 \cdot 10^{7} \mathrm{~W} / \mathrm{cm}^{2}$ ) we obtained a microrelief shown in fig. 2 . It can be seen that the size of modified zone is about $30 \mu \mathrm{m}$ (much less than beam size) regardless of $\mathrm{SiO}_{2}$ thickness. But the style of surface morphology is significantly different for samples with different oxide thickness. Thus, in case of $500 \mathrm{~nm}$ dioxide thickness a tip formation occurs in the middle of irradiated zone. Such type of morphology is not found in case of thinner $\mathrm{SiO}_{2}$ layer. The height of a tip is about $200 \mathrm{~nm}$. The size of modified area and the height of a tip, as expected, increase with a growth of pulse energy.

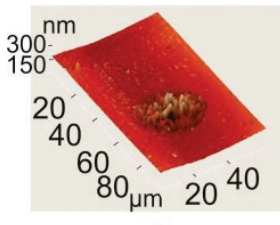

a

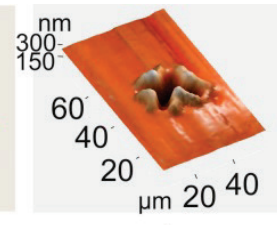

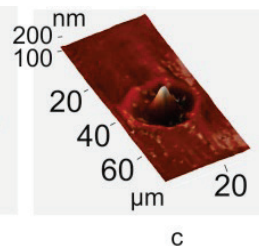

Fig.2 Microrelief, obtained after irradiation by single pulses, for samples with different oxide thickness: $\mathrm{a}-35 \mathrm{~nm}, \mathrm{~b}-150 \mathrm{~nm}, \mathrm{c}$ $-500 \mathrm{~nm}$

After irradiation of samples at $\mathrm{x}$-axis overlapping mode microstructures shown in fig. 3 were observed. Processing was carried out by pulses with energy $0.13 \mathrm{~mJ}(\mathrm{q}=$ $\left.1.15 \cdot 10^{7} \mathrm{~W} / \mathrm{cm}^{2}\right)$ on the scanning speed $\mathrm{v}=100 \mathrm{~mm} / \mathrm{s}$ at pulse repetition rate $\mathrm{f}=50 \mathrm{kHz}$. The pulse energy was reduced compared with the previous experiment, in order to avoid a destruction of an oxide film in the middle of line. The width of structured line $1_{0}$ is about $30 \mu \mathrm{m}$. A microrelief, obtained on samples with $35 \mathrm{~nm}$ oxide thickness, composed of rather chaotic cavities and protrusions. With increase of oxide thickness to $150 \mathrm{~nm}$ the microrelief becomes more regular and gets a herringbone structure, which is oriented in the scan direction. In case of $500 \mathrm{~nm}$ oxide thickness the situation is qualitatively changing. The fig. $3 \mathrm{c}$ shows that obtained microrelief represents a full wave period on sample's surface. Also, it can be noted that typical height of microstructures increases with increase of oxide thickness.

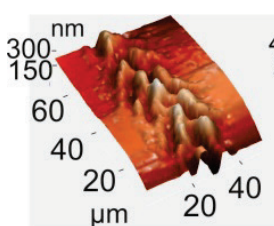

a

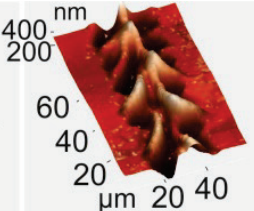

b

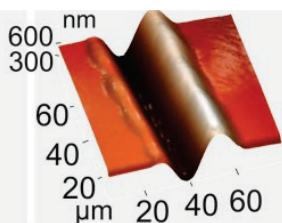

Fig.3 Microrelief, obtained in x-axis overlapping mode, for samples with different oxide thickness: $\mathrm{a}-35 \mathrm{~nm}, \mathrm{~b}-150 \mathrm{~nm}, \mathrm{c}$ $-500 \mathrm{~nm}$

The most interesting, in our opinion, results, were obtained by irradiation with both axis overlapping. Fig. 4 shows microstructures formed on $\mathrm{Si} / \mathrm{SiO}_{2}$ structure surface through $\mathrm{y}$-axis overlapping lines $\left(\mathrm{L}_{\mathrm{y}}=0.4 \mathrm{l}_{0}\right.$, where $\mathrm{l}_{0}$ is a width of single structured line), obtained in previous experiment, without scan direction changing (see fig 1a). It can be seen that in case of 150 and $500 \mathrm{~nm}$ oxide thickness regular plane wave-like structure is formed over the entire treated area. It is interesting that obtained structures are rotated at a certain angle to scan direction (shown by black arrow in fig. 4). Rotation of structures is observed if $\mathrm{L}_{\mathrm{y}}<$ $0.51_{0}$. Period of waves increases with increase of oxide thickness. The period is about $15 \mu \mathrm{m}$ for $150 \mathrm{~nm}$ oxide and about $36 \mu \mathrm{m}$ for $500 \mathrm{~nm}$ oxide. In case of $35 \mathrm{~nm}$ oxide thickness the formation of wave-like structure is nearly invisible. This fact indicates an important role of $\mathrm{SiO}_{2}$ in the formation mechanism of obtained structures. It should be noted, that orientation of wave-like structure is not related with a crystallographic orientation of samples surface.

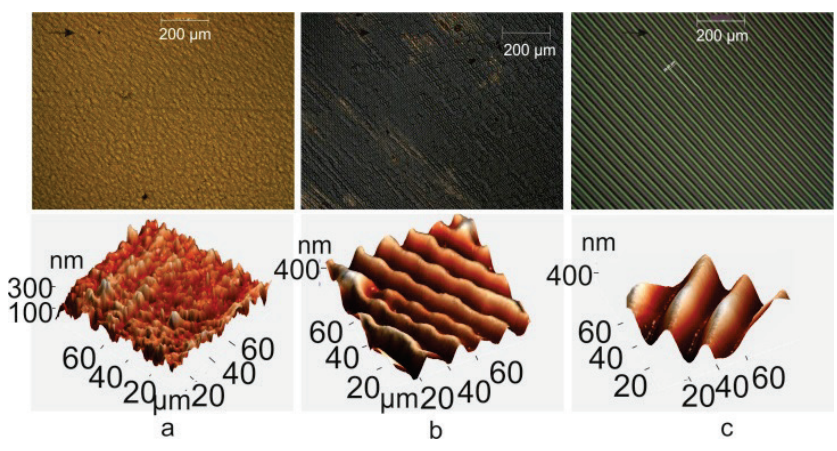

Fig.4 Microrelief, obtained in an overlapping mode along both axes without scan direction change, for samples with different oxide thickness: $\mathrm{a}-35 \mathrm{~nm}, \mathrm{~b}-150 \mathrm{~nm}, \mathrm{c}-500 \mathrm{~nm}$

It was found that change of the scan direction to opposite when laser beam passes to a next line (two directional scan, see fig $1 \mathrm{~b}$ ) changes morphology style significantly. As it can be seen in fig. 5 a plane wave like structures are not observed. Microrelief gets a herringbone structure formed over the entire treated surface.
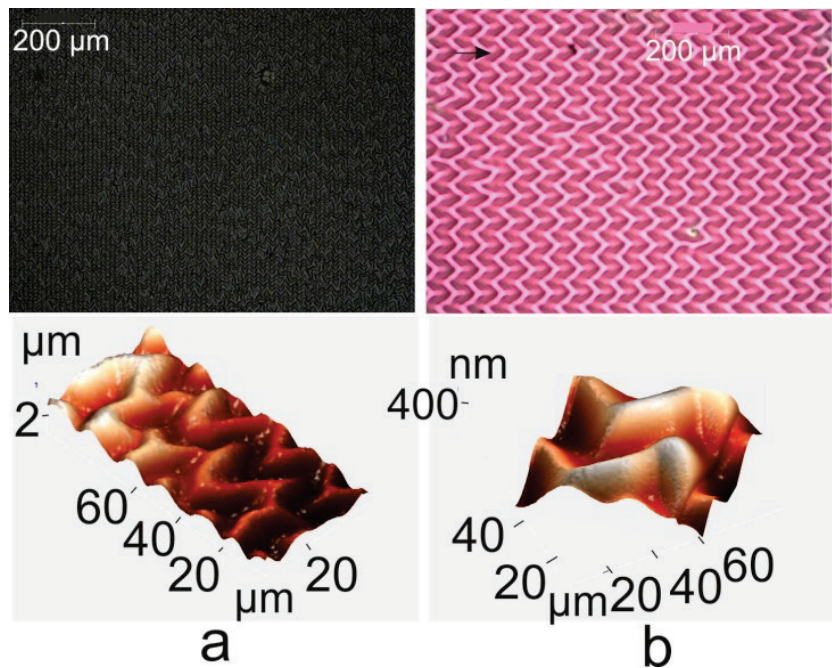

Fig.5 Microrelief, in an overlapping mode along both axes with scan direction change, for samples with different oxide thickness: $\mathrm{a}-150 \mathrm{~nm}, \mathrm{~b}-500 \mathrm{~nm}$ 
To understand an influence of surface morphology on electro-physical properties capacitance-voltage $(\mathrm{C}-\mathrm{V})$ and current-voltage (V-A) characteristics were measured. For $\mathrm{V}$-A characteristics measurements we used the following system of probe contacts: 4-probe contact to the back side of the plate and movable tungsten probe with micron sharpening to oxide side. For $\mathrm{C}-\mathrm{V}$ characteristics measurements the tungsten probe was replaced by In-Ga contact. Fig. 6 shows typical high frequency $(\omega=1 \mathrm{MHz})$ $\mathrm{C}-\mathrm{V}$ characteristic, normalized to the maximum value, measured on irradiated n-type silicon plate with $150 \mathrm{~nm}$ oxide thickness. It can be seen that there is a significant modification of $\mathrm{C}-\mathrm{V}$ characteristic. Displacement of curve along the voltage axis relative to original one indicates a change of concentration of structural defects, responsible for the magnitude of charge $\Delta \mathrm{Q}_{\mathrm{f}}$ created in $\mathrm{SiO}_{2}$. The change in the angle of inclination of the curve in the area of transition from inversion mode to saturation mode indicates a change in surface state density $\Delta \mathrm{N}_{\mathrm{ss}}$ near the interface between silicon and oxide. Capacity oscillations, which are typical for silicon nanoclusters in oxide layer, were not found.

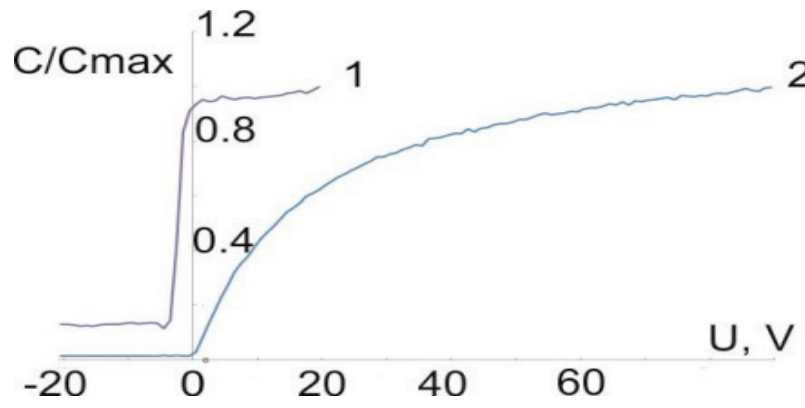

Fig 6 Typical high frequency $\mathrm{C}-\mathrm{V}$ characteristic of modified area: 1 - initial sample, 2 - irradiated sample

Earlier, authors of work [9] have already drawn attention to generation of structural defects, responsible for $\Delta \mathrm{Q}_{\mathrm{f}}$. and $\Delta \mathrm{N}_{\mathrm{ss}}$ change in $\mathrm{Si} / \mathrm{SiO} 2$ structure under the long action (about ten seconds) of ytterbium pulsed laser radiation. In this case laser irradiation leads to plastic deformation, which is expressed in an appearance of a net of slip lines, which represents steps formed on places where dislocations rise onto a surface. In our case it is not found, and observed morphology has another nature.

Measurements of current-voltage characteristic allowed determining of breakdown voltage for laser modified area. It was found that breakdown voltage is slightly reduced (relative change is about $10-20 \%$ ) after microstructuring. Such reduction can probably be associated with a decrease in the thickness of oxide layer. Indeed, the formation of microrelief leads to increase in surface area, resulting in decrease in $\mathrm{SiO}_{2}$ thickness, if oxide volume is constant. Alternatively it could be an influence of an electric field increase at the maximums of the microrelief.

\section{Microstructuring mechanism discussion}

It is important to know typical temperatures to which sample is heated to understand the mechanism of microrelief formation. In our case it is difficult to use standard experimental methods for temperature measuring (such as an infrared camera) due to very fast temperature oscillations. So it is advisable to use theoretical methods for temperature calculations.

In the basis of a model, which describes heating of silicon samples by series of nanosecond pulses, it is proposed to put an approach, developed in the work [10]. According to this approach it is necessary to take into account complicated dynamics of absorbed energy transfer into lattice due to nonradiative recombination of electrons excited in conduction band through interband absorption. Also, increase of an absorption by free carriers should be considered. Oxide film has not influence with a thermal physics of the process due to its small thickness and transparency. So the system of equations to be solved consists of a heat conduction equation, a free electron diffusion equation (which considers recombination) and an equation, which defines laser power density distribution inside the sample:

$$
\begin{aligned}
& c \rho \frac{\partial T}{\partial t}-k \Delta T=S_{T} \\
& \frac{\partial N}{\partial t}-D \Delta N=S_{N}-\frac{N}{\tau} \\
& -\frac{\partial q}{\partial z}=\left(\alpha_{V}+\alpha_{N}\right) q \\
& S_{T}=\alpha_{N} q+\alpha_{V} q\left(1-\frac{E_{g}}{\hbar \omega}\right)+\frac{N}{\tau} E_{g} \\
& S_{N}=\frac{\alpha_{V} q}{\hbar \omega} \\
& \alpha_{N}=\sigma N \\
& \left.\frac{\partial T}{\partial z}\right|_{z=0}=\left.0 \quad \frac{\partial T}{\partial z}\right|_{z=H}=0 \quad T(x \rightarrow \infty)=T(y \rightarrow \infty)=T_{0} \\
& T(t=0)=T_{0} \\
& \left.\frac{\partial N}{\partial z}\right|_{z=0}=\left.0 \quad \frac{\partial N}{\partial z}\right|_{z=H}=0 \quad N(x \rightarrow \infty)=N(y \rightarrow \infty)=0
\end{aligned}
$$

$N(t=0)=0$

$q(z=0)=(1-R) q_{0}$

where $\mathrm{T}=\mathrm{T}(\mathrm{x}, \mathrm{y}, \mathrm{z}, \mathrm{t}), \mathrm{N}=\mathrm{N}(\mathrm{x}, \mathrm{y}, \mathrm{z}, \mathrm{t}), \mathrm{q}=\mathrm{q}(\mathrm{x}, \mathrm{y}, \mathrm{z}, \mathrm{t}$,$) are$ temperature, concentration of free carriers and laser power density distribution, $\mathrm{c}=790 \mathrm{~J} /(\mathrm{kg} \cdot \mathrm{K})[11]$ - heat capacity, $\rho=2330 \mathrm{~kg} / \mathrm{m}^{3}[11]$ - density, $\Delta$ - Laplace operator, $\mathrm{k}=40$ $\mathrm{W} /(\mathrm{m} \cdot \mathrm{K})[11]$ - heat conduction coefficient, $\mathrm{S}_{\mathrm{T}}$ - heat source, $\mathrm{S}_{\mathrm{N}}$ - free carries source, $\mathrm{D}=10^{-3} \mathrm{~m}^{2} / \mathrm{s}[10]-$ free carriers diffusion coefficient, $\tau \sim 10^{-6} \mathrm{~s}[10]-$ characteristic time of free carriers nonradiative recombination, $\alpha_{\mathrm{V}}=$ $2 \cdot 10^{3} \mathrm{~m}^{-1}[10]-$ interband absorption coefficient, $\alpha_{\mathrm{N}}-$ free carriers absorption coefficient, $\sigma \sim 4 \cdot 10^{21} \mathrm{~m}^{2}[12]-$ free carriers absorption cross section, $\mathrm{E}_{\mathrm{g}}=1.1 \mathrm{ev}$ - bandgap, $\mathrm{R}$ $\sim 0.8$ (measured), $\mathrm{q}_{0}-$ incident power density.

This system was solved by numerical finite-difference method.

The results of calculations are shown in fig. 7. Fig. 7a represents the temperature-time relationship of a point, situated in the middle of scanning line in the mode, in which lines shown in fig. 3 were obtained (x-axis 
ovelapping). This graph shows that sample haven't got enough time to cool down between pulses, and heat accumulation effect occurs. Maximal temperature is about $1950 \mathrm{~K}$ and it exceeds silicon melting temperature $\left(\mathrm{T}_{\mathrm{m}}=\right.$ $1687 \mathrm{~K})$ but it is not enough for $\mathrm{SiO}_{2}$ destruction. The width of melted area is about $28 \mu \mathrm{m}$ (see fig. 7b). This result coincides with a width of microstructured lines, obtained in experiments $(\sim 30 \mu \mathrm{m}$, see fig. 3$)$. This agreement is preserved under variations of laser parameters. Fig 7c shows a comparison between widths of melted area obtained from calculations and microstructured line at different single pulse energies. On the basis of observations and calculation we can conclude, that microstructures formation is accompanied by $\mathrm{Si}$ melting under $\mathrm{SiO}_{2}$ layer, which becomes soft at considered temperatures and takes the given shape easily.

The obtained structures can be hypothetically explained by a following scenario. During Si melting the $\mathrm{Si}-\mathrm{SiO}_{2}$ interface moves down due to decrease of $\mathrm{Si}$ specific volume at melted phase. So, after the melting surface looks like a concave meniscus covered by oxide. Due to radial thermal gradients a viscosity of $\mathrm{SiO}_{2}$ in the center of melted area is smaller than at the periphery. The difference may be significant due to exponential temperature dependence of viscosity: $\eta=\eta_{0} \exp \left(-E_{\eta} / R_{0} T\right)$, where $\eta_{0}-$ constant, $E_{\eta} \sim 500 \mathrm{~kJ} / \mathrm{mol}$ [13], $R_{0}-$ gas constant. According to this relation the viscosity at the periphery $\left(\mathrm{T} \sim \mathrm{T}_{\mathrm{m}}=1687 \mathrm{~K}\right.$ ) should be about 50 times more than in the center of melted area $(\mathrm{T} \sim 1900 \mathrm{~K})$. At a cooling stage the $\mathrm{SiO}_{2}$ on the brink of melted area resists to expansion of the crystallized silicon. Thus due to a high speed of these processes an extrusion of the melt to the center and tip formation takes place (see fig. 2c). This mechanism indicates the role of $\mathrm{SiO}_{2}$ : in case of thin oxide

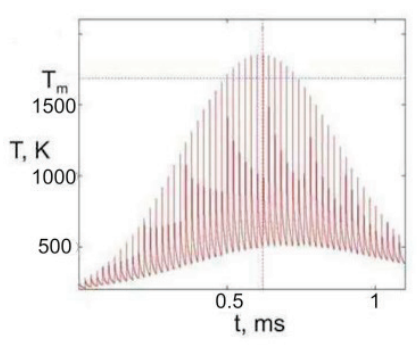

a

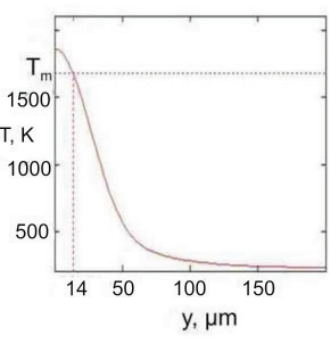

b

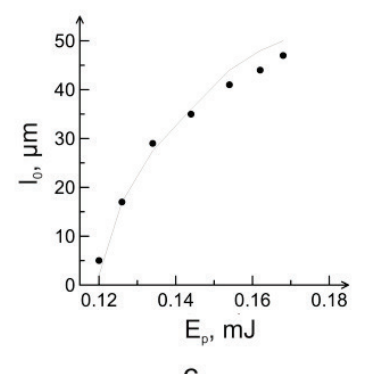

c

Fig.7 Results of theoretical calculations: a - temperature-time relationship of a point, situated in the middle of scanning line on a surface, $b$ - transverse surface temperature distribution in time, when maximum temperature is achieved, c - comparison of width of melted area obtained from calculations (line) with width of microstructured line at different single pulse energies (dots, $\mathrm{x}$ axis overlapping mode, $\mathrm{v}=100 \mathrm{~mm} / \mathrm{s}, \mathrm{f}=50 \mathrm{kHz}$ ) layer the described effect should not be strongly demonstrated. Indeed, in case of $30 \mathrm{~nm}$ oxide thickness the tip formation was not observed (see fig. 2a). Described phenomena may also be accompanied by Marangoni effect as it was observed by authors $[14,15]$. It can satisfactory explain the single pulse action. We believe that physical phenomena which lead to the formation of microrelief obtained in modes with spots or lines overlapping are the same. At the same time in some cases deviations from simple spot interference were obtained (for example, in the transition from fig. $2 \mathrm{c}$ to fig. $3 \mathrm{c}$ a shift of the maximum position can be seen).

In order to better appreciate all related phenomena a more complete theoretical model should include a generation of thermomechanical stresses near the interface between silicon and oxide, melting and crystallization processes, accompanied by specific volume changes, hydrodynamic features of molten silicon flow under thin oxide film etc. A detailed theoretical study of mentioned factors will reveal the most important of them and propose a complete model of microstructures formation on the surface of $\mathrm{Si} / \mathrm{SiO}_{2}$ structure under the action of pulsed laser radiation.

\section{Conclusions}

Irradiation of $\mathrm{Si} / \mathrm{SiO}_{2}$ structure by a scanning beam of pulsed radiation of ytterbium fiber laser leads to formation of regular wave-likes structures. Its period depends on an oxide thickness. Such surface morphology modification is accompanied with changes in capacitance-voltage characteristics, which indicate a generation of structural defects responsible for creation of spatial charge and surface states in $\mathrm{SiO}_{2}$. A comparison between experimental data and theoretical calculations makes it possible to conclude, that surface microstructuring is accompanied by a $\mathrm{Si}$ melting under $\mathrm{SiO}_{2}$ layer and its resolidification.

\section{Acknowledgments}

This work was supported by the Russian Scientific Fond Grant № 14-12-00351 (on 50\%), the RFBR grant № 13-02-00033, the President of the Russian Federation Grant №. NSH 1364.2014.2 and the Government of the Russian Federation Grant №. 074-U01.

Authors thank V. Meshalkin for C-V and V-A characteristics measurements.

\section{References}

[1] A.Y. Vorobyev, C. Guo., Appl. Surf. Sci., 257, (2011) 7291.

[2] W.J. Mandeville. M.K. Shaffer, Y. Lu, D. O’Keefe, R.J. Knize., Appl. Phys. A, 104, (2011) 755.

[3] Y. Han, S. Qu. Chemical Physics Letters, 495, (2010) 241.

[4] C. T. Huynh, A. M.Skvortsov, A. A. Petrov, Proc. SPIE, 9065, (2013) 90650T-1.

[5] C. T. Huynh, V. P. Veiko, A. M. Skvortsov, A. A. Petrov, Proc SPIE, 9065, (2013) 90650U-1.

[6]V. P. Veiko, A. M. Skvortsov, V. I. Sokolov, Q. T. Pham, R. A. Khaletski, E. I. Efimov, Proc. SPIE, 7996, (2011) 79960S-1. 
[7] S. Tivali, F. Rana, K. Chan, H. Hanafi, C. Wei, D. Buchanan, IEEE Int. Electron Devices Meeting Tech.Dig, (1995) 521.

[8] Y. Yang, L. Xu, F, Yang, W. Liu, J. Xu, Z. Ma, K. Chen, Journal of Non-Cristalline Solids, 356, (2010) 2970.

[9] A. Skvortsov, V. Veiko, C. T. Huynh, R. Khaletskiy, Proc. SPIE, 9065, (2013) 90650S-1.

[10] M. Libenson:"Laser-induced optical and thermal processes in condensed medium and its reciprocal influence" ("Science", St.-Petersburg, 2007) p.423. [In Russian]
[11] I. Grigoriev, E. Meilikhov: "Handbook of Physical Quantities" (“CRC Press", Boca Raton, 1997) p.1568 [12] R. Dyukin, G. Martsinovskiy, G. Shandybina, E. Yakovlev, I. Nikiforov, I. Guk., Journal of Optical Technology, 78, (2011) 558.

[13] V. Leko, O. Masurin: "Properties of Quartz Glass" ("Science", Leningrad, 1985) p. 167. [In Russian]

[14] S. C. Chen, D. G. Cahill, C. P. Grigoropoulos, J. Heat Transfer, 122, (2000) 107.

[15] Y. Lu, S. Theppakuttai, S. C. Chen, Appl. Phys. Lett., 82, (2003) 4143.

(Received: June 19, 2014, Accepted: June 15, 2015) 